\title{
Use of Social Media to Support Nursing Students' Learning in Zambia
}

\author{
Ruth Wahila, Lonia Mwape, Kestone Lyambai, Marjorie Kabinga-Makukula \\ School of Nursing Sciences, University of Zambia, Lusaka, Zambia \\ Email: ruth.wahila@unza.zm
}

How to cite this paper: Wahila, R., Mwape, L., Lyambai, K., \& Kabinga-Makukula, M. (2018). Use of Social Media to Support Nursing Students' Learning in Zambia. Creative Education, 9, 1237-1251.

https://doi.org/10.4236/ce.2018.98092

Received: May 4, 2018

Accepted: June 26, 2018

Published: June 29, 2018

Copyright (ㅇ 2018 by authors and Scientific Research Publishing Inc. This work is licensed under the Creative Commons Attribution International License (CC BY 4.0).

http://creativecommons.org/licenses/by/4.0/

\begin{abstract}
This study seeks to explore the use of social media to support the learning of nursing students in Zambia. Data was collected from the WhatsApp and email conversation chats involving 76 nursing students at the University of Zambia School. The content of the conversation chats was analyzed in terms of common themes, patterns and interrelationships. It was established that nursing students can take a leading role in empowering themselves by taking charge of their continued learning by using social media responsibly. Key findings that emerged from the WhatsApp and e-mail discussions are: Knowledge enhancement and sharing of best practices were significant in the WhatsApp Group, Virtual Classroom community, was significantly stronger in the WhatsApp group, WhatsApp group had a minimally more positive placement experience, other measures (social capital/knowledge application/learning dimension community) did not differ significantly. The use of social mobile media is not only limited to professional nurses but also nursing students. As the training of nurse professionals evolves in the midst of high technology use, more and more students may seek to prefer the use of social mobile media as a tool for continuous learning. In comparison to the email platform, students in the WhatsApp were able to maintain conversations up to the end of the allocated period of the study. The information gathered from this project can be useful to fostering a unified understanding of professional knowledge and a feeling of belongingness among nursing students.
\end{abstract}

\section{Keywords}

Social Media, Nursing, Learning

\section{Background}

Social media usage in education has been seen to have great potential. Social 
media refers to "forms of electronic communication (such as websites for social networking and microblogging) through which users create online communities to share information, ideas, personal messages, and other contents such as videos" (Webster Dictionary, 2017). Apart from the use of social media in sharing information, its different kinds of tools are also used to share documents, work in progress and learn from videos which are good applications to use in nurse training institutions. According to previous research, 53 percent of nursing schools reported using social media applications and WhatsApp had been used in both theory and practical aspects of education (Peck, 2014). Social media is considered as developing communication skills among students and between students and faculty. It enables group learning and develops social skills relevant to nursing. Incorporating social media into the nurse training programs is likely to allow a diverse group of interested nursing learners to engage in creating and developing content that is significant as well as to gather online and to share knowledge, information and opinions relating to the core aspects of the profession they are embarking on. In view of the fact that nursing is a science and an art, it is therefore imperative that social media technologies are incorporated in nursing education in order to offer the capability to each student to both receive and create content that would lead to lifelong learning.

Social media in nursing education can thus be used for four main purposes: communicating with students; nurturing the social atmosphere; creating dialogue and encouraging sharing among students; and as a learning platform. Most importantly, social media is being used in a variety of ways to engage students, to help them apply the knowledge they are gaining, which may ultimately empower them to be responsible and accountable for their learning. Research on learning demonstrates that students only retain $10 \%$ of what they hear, whereas they retain up to $75 \%$ of material that they have an opportunity to practice (Lalley \& Miller, 2007). In the complexity of nurse training, the use of such an interactive media can help students realize that there are many active learning methods, and that having the teacher provides all of the information is not the best way. Further, with the continuing need to meet ever-changing nurse training guidelines and standards, the student's ability to connect with other nursing students undergoing the same clinical experience may be key to staying motivated and achieving success. Thus, use of social media has gained recognition as one of the innovative teaching and learning methods for nursing students worldwide.

It is necessary to switch from the traditional lecture and questions/answers approach to better use the various social media tools to meet students' needs and expectations. These needs include increased access to the teacher and fellow students as well as course related and data information. This seems to be true for nurse learners as many of them may be faced with challenging developmental contexts often marked by isolation and a lack of belongingness. Such scenarios may impede knowledge retention among the learners. 


\section{Materials and Methods}

\subsection{Purpose}

The purpose of this study was to investigate the use of social media to educate, connect and empower nursing students undergoing training at the University of Zambia. It sort to determine scientifically the effects of social media based interventions in terms of enhanced retention, integration and application of training knowledge and reduced feelings of isolation.

It was hoped that the use of social media would complement traditional approaches to teaching and learning. Effective instruction builds knowledge between students learning and learning objectives of the course. Using social media is likely to engage students, aid students retention of knowledge, motivates interest in the subject matter and illustrate the relevance of many concepts.

\subsection{Study Setting}

This study was conducted at the University of Zambia, School of Nursing Sciences. The University of Zambia was chosen as a study site because it is the oldest and highest public training institution for nurses in Zambia. Zambia being in low resource limited country where shortage of teaching is prominent, the use of social media is likely to incorporate as many students as possible who are in need of nursing education.

\subsection{Sample}

A total of 76 (fourth year and fifth year) nursing students at the University of Zambia School of Nursing Sciences were recruited to participate in the study. All the participants consented to take part in the study but 14 (18.4\%) withdrew in the process. The study population were all nursing students on clinical placement and the accessible population were all the students undergoing teaching practice placement. During the teaching practice placement period, students practice at various nursing training institutions for students pursuing a diploma or certificate in nursing. This means that the students are away for a period of seven weeks from their usual training institution. The connections that the students would have made among themselves usually disintegrate during this period. In view of this they may feel isolated from their teachers and fellow students.

All the 76 students who were due for teaching practice placement were purposively selected to participate in the study to ensure a representative sample. Consenting students were randomly allocated to either the WhatsApp (intervention) or the e-mail (control) cohorts with each group having 38 members. The WhatsApp group was further subdivided into two (SMMS 1 and SMMS 2) in order to enhance effective moderation.

\subsection{Data Collection}

Data was collected from the conversation chats of the WhatsApp messenger 
group and the email group. Both the WhatsApp Messenger and e-mail group discussions were moderated by the lecturers. An introductory session was held with all the groups and the ground rules were set up. The Moderators controlled the discussions and ensured that ground rules set were adhered to by all participants. On a weekly basis, different discussion topics were posted and all participants were encouraged to fully contribute so that others can learn. The topics being posted were derived from the Mini curriculum specifically developed to guide the moderation process. The curriculum comprised of modules in nursing education and HIV/AIDS management. Nursing education topics were selected in order to enhance their knowledge during teaching practice while HIV/AIDs was included because this condition is very common in our settings.

The study lasted for a period of 7-weeks and at the end of the intervention, a self-administered questionnaire was administered to all participants. The aim of the end of intervention survey was to evaluate the participants' knowledge, experiences and thoughts using WhatsApp Messenger and e-mail discussion group in supplementing their learning experience. However, the survey only yielded 52 responses from the participants.

\subsection{Data Analysis}

Data was extracted from the WhatsApp and e-mail conversation chats and analysed in Microsoft Office 2013. The study considered the degree of participation from group members and the content of the conversation. The content of the conversation chats was analysed in terms of common themes, patterns and interrelationships. Most of the data analysed was extracted from the WhatsApp group as the e-mail group interactions and communication ceased after one week of engaging with them despite initiation of a discussion topic by the moderator.

\section{Results}

Findings expressed in this manuscript are based on the qualitative data only. The authors recognize the role of nursing students in empowering themselves to take charge of their continued learning by using social media responsibly. The key findings that emerged from the WhatsApp and e-mail discussions among the nursing students are:

- Knowledge enhancement and sharing of best practices was significant in the WhatsApp Group.

- Virtual Classroom community (learning dimension) was significantly stronger in the WhatsApp group.

- WhatsApp group had a minimally more positive placement experience.

- Other measures (social capital/knowledge application/learning dimension community) did not differ significantly.

\subsection{Knowledge Enhancement and Sharing of Best Practices}

One of the key notable findings of this aspect of the study was that students in 
the WhatsApp group were able to share knowledge they had acquired in class and were able to share some of the best practices of teaching that seemed to have had a positive impact on facilitating clinical placement learning. Such findings can be shown by the conversations below.

Student 4: Am teaching Medicine and Fundamentals of Nursing and both courses ... one of the principles which I feel suits these courses is LEARNING IS AN ACTIVE PROCESS-TO STIMULATE THE STUDENTS I NEED TO BE SEEN TO BE ACTIVE AS A TEACHER BEFORE I TRANSFER THE ACTIVITY TO THE STUDENTS.

Student 12: And it worked very well?

Student 4: Have seen that when am just talking students don't follow, but when I have an appropriate visual aid for each component of the topic stimulates the students to follow.

One of supervisor always reminds me that I should be walking through the class and point at students randomly.

Apart from that, I have changed the way I summary my teaching, I divide the class into groups and give each group a component I have taught to explain it the class. That is keeping the students active.

Student 12: I agree with Student 4, I also don't summarize the lesson but give it to students to do so except I don't put them in groups, this helps me to evaluate my teaching (outcome).

And its working out well.

Student 4: Yesterday I was teaching physical examination, my students looked very low ... asked them why they told me that they were preparing for a test, cracked a few jokes with them, immediately I clicked on my first visual aid the class was back to life again ... teaching is indeed an art!

Student 12: One thing that I have employed is good organization of my work and this helps the students to follow.

Student 14: Am teaching obstetrics and neonatology under midwifery as well as surgery. One principle I have been using is return demonstration on mechanism of labour each time am teaching obstetrics. This has made the student midwives to be practicing in readiness for my lectures cause I point at random thereby facilitating learning.

Student 15: Madam \& fellow studentsim very grateful for your powerful contributions. We are actually employing the assignment method, small group discussions \& individual assignments, the challenge now is that we have more assignments to attend to everyday.

I ve sometimes brought in the tribal cousinship, lozi vs tonga, bemba \& easteners during presentations, ive seen students loosen up \& interact, eventually enjoying class together.

Another way, for example in during today's $A \&$ \& session, I allowed the students to freely suggest when to have their short breaks \& they unanimously agreed on hrly breaks. 
Student 5: For me I have been praising the students that answer correctly.for those with above average answers I have been asking the fellow students to clap for them.

Student 16: For me ... I have identified some few students who $r$ not active in class so in all my lectures I make sure that they participate by asking them questions $n$ also contributions concerning the topic am teaching them ...

Student $17: \square$ I have learnt that interacting with students helps the learning process, I further want to incorporate role play as I will be teaching, just to see how they will learn.

\subsection{Virtual Classroom Community}

A virtual classroom is a teaching and learning environment where participants can interact, communicate, view and discuss presentations, and engage with learning resources while working in groups, all in an online setting. The Virtual Classroom Community which may also be referred as Virtual Learning Community is best when teachers participate by uploading resources, answering each other's questions on the groups' page, commenting on videos and other resources, and recommending each other's posts. Educational interaction, communication and discussion of presented topics was observed in the WhatsApp group. Students in the WhatsApp group were able to engage in discussions on topics specified, upload resources as observed by the sharing of the diagrammatic presentation of a concept map and could recommend each other's point of view. These findings could be substantiated by the following extracts:

Student 10: From what I understand, concept mapping is a tool that allows the teach or students to visually depict a system of relationship by creating a map in which node represent ideas or facts.

It forces students to identify connections and apprehend them more deeply. In other words it promotes critical thinking.

Student 4: The organization and presentation of knowledge and ideas using graphs or pictures.

Student 2: Relating it to what we do in research, where you have abstract ideas (concepts) then you illustrate them in picture, graphics or diagrams in order to explain them better!

Student 4: This is good revision, reflecting on what we are discussing is helping me to evaluate my teaching and remodel my teaching methodologies.

Moderator. We will look at Problem Based Learning tomorrow as the first innovative method. So let people start reflecting on it in readiness for tomorrow.

Moderator. What is PBL?

Student 19: PBL is a way in which students are given topics, they go to research, write notes and present to the fellow classmates.

In short self-teaching.

Student 5: Pbl is an innovative method of teaching where by students are given jumps or problems that they need to solve while the supervisor guides.

Moderator. How can we use PBL in nursing education? 
Student 5: We can use it in promoting critical thinking among student nurses.

It is a good method yes. I have tried it with the midwifery student in firm of assignments that we have discussed in the following lecture ... but the challenge has BN that the school hasn't adopted it as a method of instruction.

Student 4: Despite PBL swallowing a lot of time, it is to the benefit of students for it encourages CRITICAL THINKING.

Student 10: Yesit helps students to become directors and managers of their learning process.

Student 15: Teachers too need to be on their toes to push students at all times, hence not suitable for lazy teachers, but resilient ones.

Student 5: All in all sir despite the disadvantages ... the advantages of this method outweigh the disadvantages.

Student 15: Correct Mr K, \& I suggest that it be implemented in all the nursing schools.

Student 5: Yes.

Student 15: We need nusres that solve problems, give leadership direction \& confident at the same time, to gain back the lost confidence in our proffession among our people. Viva Pbl, Viva Pbl.

I salute your contributions, I ve enjoyed. Be blessed.

\subsection{Teaching Practice Placement Experience}

Exposure to teaching practice is one of the most challenging experiences for nursing students pursuing a Bachelor of Science in nursing degree. During this period, students may relive their own experiences as students and those of their own teachers in a learning environment. Such a recall may either ignite enthusiasm or anxiety. The thought of being exposed to teaching practice placement area for the first time may also bring about mixed feelings of stress, fear and zeal amidst high expectations from supervisors and faculty. It is where they encounter the "real" side of teaching and influencing learning.

It is envisioned that the WhatsApp group found the teaching practice placement rewarding as the study revealed that the group had a minimally more positive placement experience than the e-mail group. To elicit for experiences among the nursing students, the moderator asked the students about their initial feelings upon arrival at the institution for teaching practice placement and when reporting to the Principal Tutor; their expectations during practice; if they had any fears and how to overcome them. Eexcerpts from the WhatsApp group discussion listed below demonstrate that the students' experienced an encouraging teaching practice placement environment that was initially compounded by stressful situations.

Student $1: I$ really felt nice more especially that $I$ was among the pipo in charge of the sku.

Student $2: I$ really felt like it was home, relaxed because the principal I reported to was the same principal I had when I was a student at diploma level. 
Student $3: 1$. Felt anxious, at the same time good especially that $P \mathrm{~m}$ called student tutor. I expected to be respected by students, to cooperate with teaching staff, teach students with a lot if energy.

3. Fears... challenging questions from students.

4. I have study beyond their level in order to be able to answer.

Student 2: Adjusting wasn't a problem for sure!

Student 1: I thought I was going to be sidelined but the opposit happened $\cdots I$ did just believe it was me $\cdots \square$

Student $2: M y$ fears though where real because I was told earlier that this school is doing far much better than the school I was at, Meaning as teaching staff I need to put a lot $\cdots$

Student 2: The principle I have set (with my group members though) is to make preparations for lessons in good time and consult where necessary... This is helping to overcome the fear!

Yes very much but my biggest fear was to go in class to my surprise when I was in class i enjoyed teaching such that I didn't want to come out.

Student $4:$ At first the students showed some doubts when I was introduced to them, now each time they see me they start clapping ... I love my Ndola experience!

Student 4: Good evening madam. The day was manageable ... had my first lecture at 08:00 hrs. First lecture for the day!

Student 6:Q1 I was a bit anxious. I didn't know what really goes on at this school. I was actually worried if they had enough teaching staff to supervise us but to my surprise it was the opposite.

Student 7:Q1 for me I felt unequal to the task because their expectations were so high, not until I had a feedback of the first lesson I taught.

Student 6: Very friendly we had a meeting with the PT who welcomed us. He took time to find out if we did micro teaching or we are familiar with the use of LCD and how to make power point.

I got an impression that they were ready for us and they attach seriousness to education. I mean education.

Student 5:For me the initial feelings was that since I was a student I would be intimidated $\cdots$ and this made me try withdrawing a bit from the initial activities until I got to know a bit about the coordinators ... my expectations are that I get to learn the skills of proper preparation of the lesson plans as I get ready for both the clinical and classroom lectures $\cdots$ one of my biggest fears is the feeling of receiving the SNS supervisors. Iol. I feel proper preparation and will make me get more confident with facing the DNS supervisors.

Moderator. Oh ok. Why do you feel scared when you think about the SNS Supervisors?

Student 5:Kikiki it's like just a natural feeling coming.

Student 6: Its not easy I have personally I appreciated how hard it is to be a teacher with a difference because you must put in so much of your time. 
Student 8: Initial feelings ... I asked myself how I was going to meet my objectives especially the class room lessons since we were told that students only come to class on Mondays and the next two weeks after we reported they were supposed to have end of introductory block exams but to my surprise, we were informed that time will be created for us and that made me feel we were part of the faculty.

Student 9: My feelings when I got to the School $\cdots$ Anxiety about what was expected of me $\cdots$ it has since subsisded. Though I have not taught any class room session am calmer an now looking forward to teaching.

Student 11: Haa it was very interesting especially that my students participated very well in both practical and theory even forgot that my assessor is around 1. Am just tired especially that did both in the afternoon. Did not even have my lunch bcoz of anxiousness $\square$

Student 12: Afternoon, just coming from a tiring week of interviews, had a good expedience.

Student 1: It's really tiring. But we will make it anyway.

My expectations of the school were very high but I got disappointed. The principal told us they don't have an LCD because the one they had got spoilt. And printing out handouts for students is challenging cause we have to do it from the Principals office, so when he is out you can't print out. We weren't even given working space. The positive part is that the staff members are very accommodating, making our work there easier.

Good afternoon Dr, this is the most hectic period for me from time I came into school because of lesson plan preparations where you are given the whole unit prepare and teach.

Student 21: I initially had anxiety especially that it came on a short notice. But I was happy to see my lecturers again after a while and that calmed me. When I walked into class I was very calm and delivered what I had prepared. Same with practical, I was calm and really enjoyed what I was doing. All in all it was a wonderful experience.

\subsection{Social Capital/Knowledge Application/Learning Dimension Community}

Social capital is about the value of social networks, bonding similar people and bridging between diverse people, with norms of reciprocity (Dekker \& Uslaner 2001). The resources embedded in social capital include information, ideas, leads, business opportunities, financial capital, power and influence, emotional support, even goodwill, trust, and cooperation. Knowledge application refers to those activities concerned with deploying knowledge in order to produce goods and services whereas learning dimension community may be termed as a type of learning in which individuals work interdependently toward the same goal.

The above three concepts focus on the interplay between social and emotional support, connectedness and creating a community where the sole purpose is achieved. In this context, the main purpose of the WhatsApp and e-mail groups 
was to keep abreast with the knowledge already acquired. Provision of social and emotional support together with a feeling of being attached in the group can have ripple effects on attainment of goals.

However, findings of this study reveal that offering social and emotional support may not necessarily motivate a student to share knowledge with others and also to feel a part of the group which is reflected in continuous interaction with others. Therefore, these measures did not differ significantly as provided in the following flow of information shared.

Moderator. It is good that you enjoyed the assessment despite being anxious at first. What made you to get relieved of the anxiety apart from the students being active.

Student 4: Thank you, I love them too they give me a mirror of how the day unfolds.

Student 1: Good evening. Everyone. Today I had a lesson in a large classroom. $I$ was so exhausted after the lesson as if I was running a race.

Student 2: Morning to $u$ all aducators! Jas wanted to share my xperience of the first lecture I delivered on tuesday this week ... The topic was Drug $n$ substance abuse... thanks to the moderator.. the lighter moment that $k p s$ me remembering my class is when asked a question on the commonly-locally abused substances and drugs ... U should have been there to hear the aproar …MUTOTOTO ... Lol.

Now to $u$ who' ve never come across this term, it is a traditional drug used to boost and sustain one's penile email ...

Student 11: Good evening everyone today my assessor came to assess me in both classroom and clinical.

Student 12: I had bit of rest.

Moderator. Congratulations to Students 2 and Student 6 for completing the quiz. Student $Z$ you also get another credit for setting the ball rolling, I admired your courage to take the quiz. Both Students 2 and 6 have won themselves awards. What is contained in the award will be communicated tomorrow. For now, let us ululate for Students $X$ and $Y$ as we prepare for tomorrow's school and social media activities.

Student 2: yesss!!!!!!

Student 5:

Student 18:

Student 5: Nice summary sir. I feel people need to be encouraged to participate ... personally I feel this for a is quite educative to us learning to be Nurse educators.

Student 2: This group has been quite the past few days, what is happening? $\square$

Student 20: Can someone add some RED BULL to this group, it's too quiet.

Student 5: Are we discussing the rules of the group today? $\square$

Student 19: Seems not maybe they have forgotten.

Student 5: I should think people are tired. $\otimes$

How is it going at military school? 
Student 19: Am sure so. At military we are fine, at least I have taught 5 lessons, and am enjoying the military respect. At least I know one term, permission to carry on kikikiki.

Student 5: That is good. am doing fine too just the pressures coz we have a new midwifery school that was opened a week before we reported so its quite hectic to ensure that the students meet their targets.

Student 19: Pipowere are you? Time is running away.

Student 5: Am here.

\subsection{Sharing Stories and Use of Humour}

The study has shown that students still shared humorous stories despite that one of the ground rules that was set by them stated that only educational discussions should be allowed during the period of the intervention. However, only a few statements depicted the use of humour and sharing of stories as per extracts below.

\section{Student 4:}

Journalist: "President Mulyokela, I understand you are the bread winner in your family"?

Mulyokela: "P $m$ hearing that allegation for the first time, I have heard it before, It's the work of those who want to tarnish my name ... I want to tell you that, $P$ ve never been in any competition to win bread. Ask those people who say I $m$ a bread winner where they saw me win that bread? I don't need to be a bread winner to feed my family, I can buy it with my own money. Those claiming I am a bread winner must be very careful otherwise I will sue them".

Student 12:

Student 19: Am lost did we discuss these jumps yesterday.

Student 5:

Student 19: Student 5 don't laugh, or is it the word jump which I don't understand.

\subsection{Consultations on Work Challenges}

Another theme that emerged from this study was the use of WhatsApp as a tool for consultation on challenging issues that arose during the teaching practice clinical placement. This is highlighted by the following extracts:

Student 15: Good afternoon Dr, How as a teacher, do I deal with students who have problems in grasping concepts, for example: why are vital signs very important in the immediate post opertive management of a pt?

Answer: i don't know?

I threw the question back to the students \& the class was quiet. Madam im seriously concerned.

Another question: Excuse me madam, why is urine warm?

Then, students asking questions in local languange!

These are 3 rd yr students madam, please help me. 
Complicating the problem of students being slow in grasping concepts madam is the fact that our coordinators want us to seriously stick to the stipulated for each lesson plan. How do we deal with these two challenges madam?

Student 22: I think an assignment there would make the students read more on the topic, let them go and research on topic.

Student 15: Im still waitting for help to my second challenge of course coordinators insisting that we rush through the sessions, when in fact the level of assimilation of these students is very questionable. Your comment madam.

Moderator. We will address the issue. The way to address the issue is to use a variety of teaching methods. Remember it is not how much content you give to the learners, but how much they have learnt. Like we said last time, give them the topic in advance so that they read, and when you meet they will be familiar with the concepts. The curriculum is bulky and time is limited.

\section{Discussion}

The use of Social mobile media is not only limited to professional nurses but also nursing students. As the training of nurse professionals evolve in the midst of high technology use, more and more students may seek to prefer the use of social mobile media as a tool for continuous learning. Since the overall goal of nursing students is to successfully complete training, many students may opt to use social media platforms such as WhatsApp that are user friendly. It is therefore likely that conversations in such platforms are easily initiated and maintained for the attainment of the ultimate student goal.

In comparison to the email platform, students in the WhatsApp were able to maintain conversations up to the end of the allocated period of the study. The common themes, patterns and interrelationships that were observed notably in the WhatsApp group are discussed below.

\subsection{Knowledge Enhancement and Sharing of Best Practices}

Interactions between the students revealed active sharing of knowledge learnt in the classroom setup and were able to relate on how this knowledge was influencing learning among their students. The members further related the principles of learning in a particular course and the experiences of their students. This finding is in line with Bouhnik, Deshen and Gan (2014), and Pimmer et al. (2014) who indicate that WhatsApp groups encourage sharing among students and are a good learning platform. WhatsApp may be seen to enhance learning by increasing accessibility of shared learning materials, teacher availability, and the continuation of learning beyond class hours.

Further to this, using WhatsApp further enhances learning as it comes from a range of perspectives as initiation of discussions by fellow students on topics learned in class provides for a broad range of topics shared (Mahmud, Rodriguez, \& Nesbit, 2010).

It is the knowledge change or enhancement perspective that teachers, schools, 
students or parents use, often implicitly when they decide whether learning has occurred. It is also this perspective that is used by governments, educational policy makers and providers when they are planning for and evaluating the effectiveness of the provision (Monro, 2009).

\subsection{Teaching Practice Placement Experience}

Regardless of the perspective on clinical placements, a plethora of studies have found that clinical placement experiences may influence positively on nursing students' attitudes towards the clinical setting in question Fagerberg et al. (2000), Abbey et al. (2006) Happel \& Platania-Phung (2012) and a recent review by Happel \& Gaskin (2013). Graduate nurses contend that they are more likely to apply for work in settings where they had positive experiences during undergraduate clinical placements (Edwards et al. 2004). It is therefore an important task to ensure good learning environments in all clinical settings used in nursing education.

I really felt nice more especially that I was among the pipo in charge of the sku student 3 If students are placed in a learning environment where they feel they are in charge there can be a rewarding effect. Some of the sentiments expressed by student 3; also point to a positive feeling experienced when students are regarded as "being professionals".

Felt anxious, at the same time good especially that $1 \mathrm{~m}$ called student tutor. I expected to be respected by students, to cooperate with teaching staff, teach students with a lot if energy. Fears … challenging questions from students. I have to study beyond their level in order to be able to answer.

I really felt like it was home, relaxed because the principal I reported to was the same principal I had when I was a student at diploma level-familiarity with the learning environment is a factor that can promote effective learning.

\subsection{Virtual Classroom Community}

There are a variety of factors that align with the objectives of the clinical experience and provide ways to keep the students interested. Reflection on clinical placement experiences may serve as a very vivid reminder of the key factors that promote student teachers' performance. From a practical perspective, nurse educators who guide nursing students through weeks of learning experiences see them as potential new recruits to their specialty field of nursing (Happel, 2008). This can be motivating for many students as alluded by Student 1 who stated that: I really felt nice more especially that I was among the pipo in charge of the $s k u$. Since the practice placement site is the venue where skills, knowledge and attitudes developed in the theoretical part of the curriculum are applied, developed and integrated, it is likely that a positive experience that is especially encountered in the initial stages can foster attainment of student goals.

Most of the participants still use e-mail but have experienced low compliance, probably due to the fact that many students do not check their email on a daily basis, which makes communication less effective. 


\section{Conclusion}

Social media can be a useful tool for nurse educational purposes. It can constantly try to bring out the teachers' teaching methods closer to the "real world" of students and thus provide a chance to facilitating the attainment of the students learning goals. It has been noted from this intervention that social media tools for example WhatsApp likely engage students in their own learning.

The emergency of social media has impacted significantly on how students learn and the way teachers teach in today's world. Mobile instant (multipoint) communication, as supported by WhatsApp, can enhance knowledge acquisition in placement settings, but not necessarily better than other, point-to-point technologies such as email. The learning dimension of the Virtual Classroom community was higher with WhatsApp but not for other indicators. The study also showed that WhatsApp is more preferable to the other means of communication and social networks than e-mail communication. The potential value of WhatsApp to enhance social learning indicators could not be confirmed by this study.

\section{Suggestions for Future Research}

There is need to introduce topics that had not yet been taught in the classroom setting to the intervention group. At the end of the intervention, the WhatsApp chat data should be erased prior to transferring it to the computer. Discussion points and quizzes should then be posted to the WhatsApp group so as to measure the effect of knowledge retention and application of best practices in nursing education.

\section{References}

Abbey, J., Abbey, B., Bridges, P., Elder, R., Lemke, P., Liddle, J., \& Thornton, R. (2006). Clinical Placements in Residential Aged Care Facilities: The Impact on Nursing Students Perception of Aged Care and the Effect on Career Plans. The Australian Journal of Advanced Nursing, 23, 14-19.

Bouhnik, D., Deshen, M., \& Gan, R. (2014). WhatsApp Goes to School : Mobile Instant Messaging between Teachers and Students. Journal of Information Technology Education: Research, 13, 217-231. https://doi.org/10.1016/j.iheduc.2016.06.001

Dekker, P., \& Uslaner, E. M. (2001). Introduction. In E. M. Uslaner (ed.), Social Capital and Participation in Everyday Life (pp. 1-8). London: Routledge.

Edwards, H., Smith, S., Finlayson, K., \& Chapman, H. (2004). The Impact of Clinical Placement Location on Nursing Students Competence and Preparedness for Practice. Nurse Education Today, 24, 248-255. https://doi.org/10.1016/j.nedt.2004.01.003

Fagerberg, I., Winbald, B., \& Ekman, S. (2000). Influencing Aspects in Nursing Education on Swedish Nursing Students Choices of First Work Area as Graduated Nurses. Journal of Nursing Education, 39, 211-218.

Happel, B., \& Gaskin, C. J. (2013). The Attitudes of Undergraduate Nursing Students towards Mental Health Nursing: A Systematic Review. Journal of Clinical Nursing, 22, 148-158. https://doi.org/10.1111/jocn.12022

Happel, B., \& Platania-Phung, C. (2012). Mental Health Placements in a General Health 
Setting: No Substitute for the Real Thing! Journal of Clinical Nursing, 21, 2026-2033. https://doi.org/10.1111/j.1365-2702.2011.04016.x

Lalley, J. P., \& Miller, R. H. (2007). The Learning Pyramid: Does It Point Teachers in the Right Direction? Education, 128, 64-79.

Mahmud, N., Rodriguez, J., \& Nesbit, J. (2010). A Text Message-Based Intervention to Bridge the Healthcare Communication Gap in the Rural Developing World. Technology and Health Care, 18, 137-144. https://doi.org/10.3233/THC-2010-0576

Peck, L. G. (2014). Social Media in Nursing Education. Responsible Intergration for Meaningful Use. Journal of Nursing Education, 53, 164-169. https://doi.org/10.3928/01484834-20140219-03

Pimmer, C., Brysiewicz, P., Linxen, S., Walters, F., Chipps, J., \& Gröhbiel, U. (2014). Informal Mobile Learning in Nurse Education and Practice in Remote Areas-A Case Study from Rural South Africa. Nurse Education Today, 1-14. 